\title{
Study of association of Iron deficiency anaemia and simple febrile seizures in 6-60 months children: A Case control study
}

\author{
Shah $\mathbf{H}^{1}$, Shah $\mathrm{B}^{2}$, Banker $D^{3}$, Pandya $\mathrm{D}^{4}$, Shah $\mathrm{V}^{5}$, Shah $\mathrm{A}^{6}$ \\ ${ }^{1}$ Dr Hiral Shah (MD Ped), Assistant Professor; ${ }^{2}$ Dr Bijal Shah(MD Ped), Associate professor; ${ }^{3}$ Dr Deepa Banker(MD \\ Ped) Professor, ${ }^{4}$ Dr Dhyey Pandya(3rd year Resident), ${ }^{5}$ Dr Vaibhav Shah(MD Ped), ${ }^{6}$ Dr Apoorva Shah(2nd year \\ Resident). All are affiliated with Department of Pediatrics/N.H.L Medical College,Gujarat University,India
}

Address for Correspondence: Dr Hiral Shah, Assistant Professor, Pediatrics, Sheth V.S General Hospital, N.H.L Medical, College, Ahmedabad, India, drhiralgopani79@yahoo.com; shahapoorva90@gmail.com

\begin{abstract}
Introduction: Simple febrile seizure and Iron defficiency anemia both are prevalant among children of 6-60 months of age. Lots of studies have been done to study the hypothesis linking iron defficiency as a risk factor for simple febrile seizure. Objective: To study the association between iron defficiency anemia and simple febrile seizure. Design: Prospectice case control study. Settings: In a tertiaty care teaching hospital. Participants: Total 180 age and sex matched case and controls were included in the study. Cases were children, 6 to 60 month old diagnosed as simple febrile seizures. Controls were children having febrile illness without convulsions. Methods: After taking informed consent, detail history and examination were done according to proforma in both groups. Blood investigations for iron defficency were done and WHO guidelines were used to diagnose the same. Results were noted and analysed. Results: Significant association (pvalue $<0.001$ ) was found between iron defficency anemia and simple febrile seizures. Serum ferittin level an early indicator of iron defeciency anemia was significantly low in simple febrile seizure patients. Conclusion: Thus it supports association of iron defficency anemia and simple febrile seizures, and iron supplimentation would be helpful for reducing occurance of same.
\end{abstract}

Key Words: Simple febrile seizures, Iron defficiency anemia.

\section{Introduction}

Simple febrile seizure is prevalant in 6 to 60 month of age with about $2-5 \%$ incidence.[1]. It describes seizure occurs with high grade fever without any neurologcal illness like meningitis, encephalitis, electrolyte imbalance, neurodegenrative disorders. Increasing episodes of this seizures increase various risk to child and also psychological stress to parents [2-6]. Lots of factors are studies for association of this seizures. Iron deficiency is one of the most prevalent (around 46$66 \%$ ) occruance nutritional problem among this age group children in the developing countries [7]. As iron is an important micronutrient for the production of serotonin, dopamine, gamma amino butyric acid, neurotransmitters like monoamine and aldehyde oxidase and myelinations, its deficiency may lower the seizure threshold in patients of simple febrile seizures. $[8,9]$. There are lots of hypothesis availabel linking

Manuscript received: $10^{\text {th }}$ Dec 2015

Reviewed: $30^{\text {th }}$ Jan 2016

Author Corrected; $20^{\text {th }}$ Jan 2016

Accepted for Publication: $13^{\text {th }}$ Jan 2016 iron defficency anemia as a risk factor for simple febrile seizures [10-15].Present study is aimed to know the association between these two, as iron defficency anemia is a condition which is easy to diagnose, treat, and prevent.

\section{Material and Methods}

A prospective case control study was done in department of pediatrics, Sheth V.S. General hospital, Ahmedabad during august 2012 to august 2014. Ethical clearance was obtained. Children between age group of 6-60 months, admitted with first attack of simple febrile seizure were taken as cases. AAP clincial guidelines [2 ] were taken as reference to diagnose simple febrile seizures. (seizure with fever, generalised, less then 15 minutes, no recurrence within 24 hours, neurologically healthy child, no pre or post seizure neurologic deficit, between 6 to 60 months of age). Similar age and sex matched, concurrent randomlly selected children, 
admitted with short( $<3$ days) febrile illness but without any seizures were taken as controls. Children presented with atypical febrile seizures, children having CNS infections, children with history of asphaxiadevelopmental delay- epilepsy, those children on iron supplimentaion therapy, children having hemolytic anaemia were excluded from the study.Informed consent was taken and detailed history, demographic profile and clincal examination was done according to preformed proforma. Blood investigations were done to diagnose iron deficiency anemia in both gropups.We have taken WHO guidelines [7] to diagnose iron deficency anemia (hemoglobin $<11$ gm $\%$, RDW $<15 \%$,serum ferritin $<30 \mathrm{ng} / \mathrm{ml}$ ). Hemoglobin and RDW estiamtion was done using an automated hematology analyzer (celldyn autgomated hematology analyser) and serum ferritin estimation was done by immunochemiluminescent method using Abbogg c 4100 automatic analyser. Cases and controls were compared as regards of $\mathrm{Hb}$, RDW and serum ferritin. Data were tabulated and analysed. Two sample t test was used to determine statistical significance.

\section{Results}

Total 180 cases and controls were included in study. Average age of case and control was 16 months. Common cause of fever both in case and control was respiratory tracts infections. Other cause of fever were gastroentritis, urinary tract infections in around $30 \%$ of patients of cases and control some nonspecific illness was present to cause fever. We have confirmed that positive family history of typical febrile seizure was strongly associated as a risk factor for it. ( $p$ value significant in case).

Most of the case and control groups were from lower socio economic class. We found that malnutritin was present alomst $50-70 \%$ of patients in both groups as the study was done in tertiary care hospital of developing counry most of the patients were from lower socio economic class having undernutrtion. Iron defficiency anemia was present in $63.3 \%$ of cases against $24.4 \%$ of patients in control group. ( $p$ value significant) thus even all case and controls were equally age and sex matched with almost equal socioeconomic status we found significnat occurance of iron defficency anemia in patients of typical febrile seizures this signified the association of it with simple febrile siezure as a risk factor.

Table 1: The differences in demographic characteristics among cases of simple febrile siezureand controls

\begin{tabular}{|l|l|l|l|l|}
\hline & Cases $(\mathbf{n = 1 8 0})$ & Controls(n=180) & $\begin{array}{l}\text { Crude } \\
\text { ratio(CI) }\end{array}$ & odds Value \\
\hline Age 6-12 months & $35(19.44 \%)$ & $40(22.22 \%)$ & $1.027(0.65-610)$ & 0.909 \\
\hline Age 13-60 months & $145(80.55 \%)$ & $140(77.77 \%)$ & $1.127(0.6551 .610)$ & 0.790 \\
\hline Sex Male & $115(63.88 \%)$ & $96(53.33 \%)$ & $1.35(0.81-2.23)$ & 0.238 \\
\hline Sex Female & $65(36.11 \%)$ & $84(46.66 \%)$ & $1.28(0.91-2.2)$ & 0.210 \\
\hline Respiratory tract infections & $88(48.88 \%)$ & $82(45.55 \%)$ & $1.297(0.82-2.03)$ & 0.254 \\
\hline Gastroenteritis & $28(15.55 \%)$ & $36(20 \%)$ & $1.35(0.81-2.23)$ & 0.248 \\
\hline UTI & $4(2.22 \%)$ & $8(4.44 \%)$ & $1.6(0.94-1.8)$ & 0.346 \\
\hline Nonspecific illness & $60(33.33 \%)$ & $54(30 \%)$ & $1.09(0.61-1.99)$ & 0.768 \\
\hline Family h/o simple febrile siezure & $35(19.44 \%)$ & $5(2.77 \%)$ & $\mathbf{2 . 4 6}(1.31-4.60)$ & $\mathbf{0 . 0 0 4}$ \\
\hline Complete immunisation & $33(18.3 \%)$ & $29(16.11 \%)$ & $1.17(0.72-1.89)$ & 0.535 \\
\hline Incomplete immunisation & $147(81.66 \%)$ & $151(83.88 \%)$ & $1.31(0.68-1.3)$ & 0.215 \\
\hline Social class(3-5) & $115(63.88 \%)$ & $108(60 \%)$ & $1.217(0.737-2.01)$ & 0.441 \\
\hline Malnutrition & $130(72.22 \%)$ & $102(56.66 \%)$ & $1.06(0.791-1.81)$ & 0.291 \\
\hline Iron defficency anemia & $114(63.33 \%)$ & $44((24.44 \%)$ & $\mathbf{5 . 3 4}(3.27-8.73)$ & $\mathbf{0 . 0 0 1}$ \\
\hline
\end{tabular}

Table 2: Mean levels of $\mathrm{Hb}, \mathrm{S}$. Ferritin among case with simple febrile siezure and controls

\begin{tabular}{|l|l|l|l|l|l|}
\hline \multirow{2}{*}{ Blood indices } & \multicolumn{2}{|l|}{ Cases(180) } & \multicolumn{2}{|l|}{ Control(180) } & \multirow{2}{*}{ P Value } \\
\cline { 2 - 5 } & Mean & SD & Mean & SD & \\
\hline $\mathrm{Hb}(\mathrm{g} / \mathrm{dl})$ & 9.45 & 1.61 & 11.56 & 1.8 & $<0.01$ \\
\hline S. ferritin(ng/ml) & 20.09 & 21.57 & 48.3 & 20.12 & $<0.01$ \\
\hline
\end{tabular}


The mean serum ferritin level and mean $\mathrm{Hb}$ that are marker of iron defficency anemia were significantly lower in simple febrile siezure group compared with reference group.Low serum ferritin level and low $\mathrm{Hb}$ were found to be significant risk factor $(\mathrm{p}$ value $<0.01)$ for simple febrile siezure, as shown in Table 2 .

\section{Discussion}

Febrile seizure is the most common cause of seizures in 6-60 month age group children. Incidance of this seizure vaies from 2-45 in developes countries to about $14 \%$ in developing countries like Africa[2,3,4]. Risk factors for this type of seizures has been extensively studied over last two decades.Height of temprature,history of febrile seizure in first or second degree relative, no. of fever episodes in one year, maternal consumtion of smoking and alcohol are some proven risk factors. Iron is been recognised as a very important micronutrient for neurological functioning, experiments in differnt rodent models confirm iron requirment for neurotransmitor metabolism, myelin formation, brain energy meabolism $[8,9,10]$. In children between 6 months to 2 years when iron rich nutrtion is compromised iron store is prioritised for $\mathrm{RBC}$ then brain cells and thus neurological functioning is affected.We found a strong associaction of iron defficency anemia as a risk factor for simple febrile seizure. (pvalue $<0.001$ ). we have observed that iron defficeny anemia was present in $63.3 \%$ of patients with simple febriles seizures. Similar association was observed previously in various studies $[12,13,14,15,18,19]$ they have similar observation that iron deficiency anemia was present in simple febrile seizure patients. In 1995 kobirensky et al has suggested that iron deficiency anemia lowers seizure threshold. 2006 Bidbadi et al observed no correlation between two $[16,17]$. Studies done on thalassemic patients have noted incidence of febrile seizure were much low then among children in general population [20].

We have also observed Serum ferritin level, an important indicator of body iron store, was significantly lower in children suffering from simple febrile seizures than children in the control group and is an important risk factor for the same. $(\mathrm{P}=0.001)$. The studies which had contradictory findings may be due to very small sample size, and they had taken only $\mathrm{Hb}$ level, $\mathrm{MCH}$, $\mathrm{MCV}$ for assessing iron deficiency, had not measured serum ferritin level which is a parameter to show real bone marrow iron store [6]. Ferritin is a protein carrier for iron and is the iron storage source in the body. Measuring serum ferritin level is a specific, sensitive and a reliable test for detecting iron depletion in the of serum ferritin and thus iron deficiency anemia, in simple febrile seizure group patients.
The strength of our study was using standardized criteria for diagnosing febrile seizures, and iron deficiency, concurrent enrollment of age and sex matched controls and cases, and no recall bias regarding exposure (prospective study). The study does have some limitations. As it was a hospital-based study the prevalence of exposure and outcome variables may be different from a community setting. Effect of iron treatment and follow up observation was not done.

\section{Conclusion}

In conclusion iron deficiency anemia does have strong association with simple febrile seizure and serum ferritin level is an important tool to find out the same. Various government strategies like iron plus initiative may help to reduce iron deficiency anemia prevalence in community and thus it may help to reduce occurrence of simple febrile seizures and even supplementation of oral iron in patients of simple febrile seizure will reduce further seizure episodes.

Acknowledgment: The authors would like to appreciate all the participants, children, laboratory, data analyzer, dean sir for their support.

Funding: Nill

Conflict of Interest: None

Permission of IRB: Yes

\section{References}

1. Johnston MV. Seizures in childhood. In: Kleigman RM, Behrman RE, Jenson HB, Stanton BP. Nelson Text Book of Pediatrics 18th Edition Philadelphia: Saunders Elsevier; 2007. p.2457-8.

2. Steering Committee on Quality Improvement and Management, Subcommittee on Febrile Seizures American Academy of Pediatrics. Febrile seizures: clinical practice guideline for the long-term management of the child with simple febrile seizures. Pediatrics. 2008 Jun;121(6):1281-6. doi: 10.1542/peds.2008-0939.

3.American Academy of Pediatrics Steering Committee on Quality Improvement and Management.Classifying 
recommendations for clinical practice guidelines. Pediatrics. 2004 Sep;114(3):874-7.

4. Practice parameter: long-term treatment of the child with simple febrile seizures. American Academy of Pediatrics. Committee on Quality Improvement, Subcommittee on Febrile Seizures. Pediatrics. 1999 Jun;103(6 Pt 1):1307-9.

5. Sadleir LG, Scheffer IE. Febrile seizures. BMJ. 2007 Feb 10;334(7588):307-11.

6. Waruiru C, Appleton R. Febrile seizures: an update. Arch Dis Child. 2004 Aug;89(8):751-6.

7. World Health Organization. Iron Deficiency Anemia.Assessment, Prevention and Control. A Guide for Program Managers. WHO/NHD/013;Geneva: 2001.

8. Beard J. Iron deficiency alters brain development and functioning. J Nutr. 2003 May;133(5 Suppl 1):1468S$72 \mathrm{~S}$.

9. Batra J, Seth PK. Effect of iron deficiency on developing rat brain. Indian J Clin Biochem. 2002 Jul;17(2):108-14. doi: 10.1007/BF02867982.

10. Wike WM, Kiser WR. Iron deficiency anaemia and febrile convulsions. Possible confounding factors include lead toxicity. BMJ. 1996 Nov 9;313(7066):1205.

11. Prasad AN, Seshia SS. Susceptibility to febrile seizures: more than just a faulty thermostat! Can J Neurol Sci. 2009 May;36(3):277-9.

12. Pisacane A, Sansone R, Impagliazzo N, Coppola A, Rolando P, D'Apuzzo A, Tregrossi C. Iron deficiency anaemia and febrile convulsions: casecontrol study in children under 2 years. BMJ. 1996 Aug 10;313(7053):343.
13. Hartfield DS, Tan J, Yager JY, Rosychuk RJ, Spady D, Haines C, Craig WR. The association between iron deficiency and febrile seizures in childhood. Clin Pediatr (Phila). 2009 May;48(4):420-6. doi: 10.1177/0009922809331800. Epub 2009 Feb 19.

14. Daoud AS, Batieha A, Abu-Ekteish F, Gharaibeh $\mathrm{N}$, Ajlouni S, Hijazi S. Iron status: a possible risk factor for the first febrile seizure. Epilepsia. 2002 Jul;43(7):740-3.

15. Vaswani RK, Dharaskar PG, Kulkarni S, Ghosh K. Iron deficiency as a risk factor for first febrile seizure. Indian Pediatr. 2010 May;47(5):437-9. Epub 2009 Sep 3.

16. Kobrinsky NL, Yager JY, Cheang MS, Yatscoff RW, Tenenbein $M$. Does iron deficiency raise the seizure threshold? J Child Neurol. 1995 Mar;10(2):1059.

17. Bidabadi E, Mashouf M. Association between iron deficiency anemia and first febrile convulsion: A casecontrol study. Seizure. 2009 Jun;18(5):347-51. doi: 10.1016/j.seizure.2009.01.008. Epub 2009 Feb 15.

18. Momen Ali Akbar ,Nikfar Roya ,Karimi Babak, Evaluation of iron status in 9 months to 5 year old children with febrile seizures: A Case Control Study in South West of Iran, Iran J Child Neurology Vol4 No2 Sep 2010

19. Kumari PL, Nair MK, Nair SM, Kailas L, Geetha S. Iron deficiency as a risk factor for simple febrile seizures--a case control study. Indian Pediatr. 2012 Jan;49(1):17-9. Epub 2011 May 30.

20. Auvichayapat P, Auvichayapat N, Jedsrisuparp A, Thinkhamrop B, Sriroj S, Piyakulmala T, Paholpak $\mathrm{S}$, Wattanatorn J. Incidence of febrile seizures in thalassemic patients. J Med Assoc Thai. 2004 Aug;87(8):970-3.

\section{How to cite this article?}

Shah H, Shah B, Banker D, Pandya D, Shah V, Shah A Study of association of Iron deficiency anaemia and simple febrile seizures in 6-60 months children: A Case control study : Int J Pediatr Res 2016; 3(2):86-89.doi: 10.17511/ijpr.2016.i02.03. 